\title{
$A B C$ transporters are involved in defense against permethrin insecticide in the malaria vector Anopheles stephensi
}

\author{
Sara Epis $^{1 \dagger}$, Daniele Porretta ${ }^{2 \dagger}$, Valentina Mastrantonio ${ }^{2}$, Francesco Comandatore ${ }^{1,3}$, Davide Sassera ${ }^{3}$, Paolo Rossi ${ }^{4}$,
} Claudia Cafarchia ${ }^{5}$, Domenico Otranto ${ }^{5}$, Guido Favia ${ }^{4}$, Claudio Genchi ${ }^{1}$, Claudio Bandi ${ }^{1 *}$ and Sandra Urbanelli ${ }^{2}$

\begin{abstract}
Background: Proteins from the ABC family (ATP-binding cassette) represent the largest known group of efflux pumps, responsible for transporting specific molecules across lipid membranes in both prokaryotic and eukaryotic organisms. In arthropods they have been shown to play a role in insecticide defense/resistance. The presence of $A B C$ transporters and their possible association with insecticide transport have not yet been investigated in the mosquito Anopheles stephensi, the major vector of human malaria in the Middle East and South Asian regions. Here we investigated the presence and role of $A B C s$ in transport of permethrin insecticide in a susceptible strain of this mosquito species.

Methods: To identify ABC transporter genes we obtained a transcriptome from untreated larvae of An. stephensi and then compared it with the annotated transcriptome of Anopheles gambiae. To analyse the association between ABC transporters and permethrin we conducted bioassays with permethrin alone and in combination with an ABC inhibitor, and then we investigated expression profiles of the identified genes in larvae exposed to permethrin.

Results: Bioassays showed an increased mortality of mosquitoes when permethrin was used in combination with the $A B C$-transporter inhibitor. Genes for $A B C$ transporters were detected in the transcriptome, and five were selected (AnstABCB2, AnstABCB3, AnstABCB4, AnstABCmember6 and AnstABCG4). An increased expression in one of them (AnstABCG4) was observed in larvae exposed to the LD50 dose of permethrin. Contrary to what was found in other insect species, no up-regulation was observed in the AnstABCB genes.

Conclusions: Our results show for the first time the involvement of $A B C$ transporters in larval defense against permethrin in An. stephensi and, more in general, confirm the role of $A B C$ transporters in insecticide defense. The differences observed with previous studies highlight the need of further research as, despite the growing number of studies on ABC transporters in insects, the heterogeneity of the results available at present does not allow us to infer general trends in $A B C$ transporter-insecticide interactions.
\end{abstract}

Keywords: Mosquitoes, Bioassays, Insecticide resistance, Culicidae, Vector control, ABC transporters

\section{Background}

Malaria is a major threat to human health and socioeconomic development, representing a great burden in the vast regions of the world in which this parasitosis is endemic [1-3]. WHO estimated over 200 million cases of malaria in the 99 endemic countries and around 660,000 deaths, in the year 2010 [2].

\footnotetext{
* Correspondence: claudio.bandi@unimi.it

†Equal contributors

${ }^{1}$ Department of Veterinary Science and Public Health, University of Milan, Milan, Italy

Full list of author information is available at the end of the article
}

Vector control through insecticides is a core component of malaria control programmes. However, continuous use of insecticides has led to the development of resistance in many malaria vectors around the world, which poses a serious threat to the global malaria control efforts [3-5]. Research is therefore needed to understand the molecular basis of insecticide detoxification and develop even more effective methods to delay emergence of resistance [6].

In recent years, the role of ATP-binding cassette (ABC) transporters in the defense against toxic compounds as 
pesticides has attracted a great deal of attention (reviewed in $[7,8])$. ABC transporters are ATP-dependent efflux pumps belonging to the $\mathrm{ABC}$ protein family located in the cellular membrane in both prokaryotic and eukaryotic organisms. In eukaryotic organisms, they mediate the efflux of compounds from the cytoplasm to the outside of the cell or into organelles. $\mathrm{ABC}$ proteins have been subdivided into eight subfamilies (from $\mathrm{ABC}-\mathrm{A}$ to $\mathrm{ABC}-\mathrm{H}$ ), and can transport a wide array of different substrates across cellular membranes (e.g., amino-acids, sugars, lipids, and peptides). Most of the $\mathrm{ABC}$ transporters associated with the efflux of pesticides belong to the subfamilies $A B C-B$ (also referred to as P-glycoproteins, P-gps), $\mathrm{ABC}-\mathrm{C}$ and $\mathrm{ABC}$ $\mathrm{G}$. In some cases $\mathrm{ABC}$-transporter action has also been associated with insecticide-resistant phenotypes in species of agricultural or medical importance $[7,8]$. In spite of an increasing awareness of the potential importance of $\mathrm{ABC}$ transporters in vector control, to date they have been poorly studied in detail in malaria vectors [8]. Here, we investigated the role of $\mathrm{ABC}$ transporters in the detoxification against the insecticide permethrin in the malaria vector Anopheles stephensi (Culicidae: Diptera). This mosquito species, vector of both Plasmodium falciparum and Plasmodium vivax, is one of the major vectors of human malaria in the world. An. stephensi occupies a geographic range that spans from the Middle East to South-East Asia [9]. These regions contribute to $15 \%$ of malaria cases worldwide, with an estimated 28 million people annually affected by the disease [2]. Permethrin belongs to the pyrethroid class of insecticides, which is by far the most commonly used in malaria vector-control interventions [2].

Pyrethroids act by modifying the gating kinetics of voltage-gated sodium channels, thereby disrupting neuron function, which leads to rapid paralysis and death of the insect [10]. They can enter into the insect body by ingestion and penetration into the hemolymph through the alimentary canal, or via contact with sensory organs of the peripheral nervous system [11]. Insect midgut is rich in $\mathrm{ABC}$ transporters, whose action, therefore, likely prevents permethrin to reach its target sites [8]. Furthermore, insects possess protective neural barriers (e.g. a layer of glially derived epithelial cells), where ABC transporters likely play an important role in the exchange of molecules $[12,13]$. In particular, inhibition of P-gp in Schistocerca gregaria has been shown to increase brain uptake of different drugs [13]. The involvement of ABC transporters in pyrethroid detoxification has been reported for a few insect species, such as Helicoverpa armigera [14-16], Apis mellifera [17] and Culex pipiens [18]. Up-regulation of $\mathrm{ABC}$-transporter genes has also been reported in pyrethroid resistant strains of the bed bugs Cimex lectularius [19] and of the vector mosquitoes Anopheles gambiae [20] and Aedes aegypti [21]. No protein belonging to the $\mathrm{ABC}$ transporters has yet been described in larvae of An. stephensi, nor the possible association of this class of proteins with insecticide transport has been investigated in this species. In this paper we investigated the presence and role of ABCs in transport of permethrin insecticide in larvae of An. stephensi: $i$ ) by bioassays with permethrin alone and in combination with an $\mathrm{ABC}$ inhibitor; $\mathrm{ii}$ ) by investigating gene expression profiles in larvae exposed to permethrin treatment.

\section{Methods}

\section{Mosquito samples}

The mosquito larvae used in this study were obtained from adult females of a An. stephensi colony, derived from the Liston strain. This colony has been maintained for four years in the insectary at the University of Camerino, following standard conditions: adult insects are reared at $28 \pm 1^{\circ} \mathrm{C}$ and $85-90 \%$ relative humidity with photoperiods (12:12 L-D) with a 5\% sucrose solution, and adult females are fed with mouse blood for egg laying. Eggs from this colony were put into spring water in order to obtain the larvae. Larvae were maintained in spring water and fed daily with fish food (Tetra, Melle, Germany) under the same conditions as the adults.

\section{Bioassays}

Inhibition of $\mathrm{ABC}$-transporters should lead to a higher intracellular concentration of insecticide, thus increasing larval susceptibility and insecticide efficacy [8]. In order to evaluate a potential synergy, we performed bioassays with permethrin insecticide alone and with permethrin in combination with a sub-lethal dose of the ABCtransporter inhibitor verapamil (see below for experimental determination of sub-lethal dose of verapamil). This is a calcium channel blocker, which works by competing with cytotoxic compounds for efflux by the membrane pumps [22]. All bioassays were conducted on $A n$. stephensi larvae at the third instar, according to standard protocols [23].

Groups of 25 larvae were put in $250 \mathrm{ml}$ plastic glasses with $100 \mathrm{ml}$ of spring water and different concentrations of insecticide or insecticide + inhibitor. All tests were performed in quadruple. Additional groups of larvae, treated only with water and acetone (that was used to dilute permethrin), were used as controls. Mortality was assessed at $24 \mathrm{~h}$ post-treatment and the larvae were considered dead if immobile, even after a mechanical stimulus.

In the bioassays with permethrin alone (Sigma-Aldrich S.r.l., Milan, Italy), six insecticide concentrations were used $(0.015,0.047,0.092,0.23,0.57,1.44 \mathrm{mg} / \mathrm{l})$ to have mortality in the range 1-99\%. The drug was dissolved in acetone and then diluted in water to obtain the test solutions. The bioassays with permethrin in combination with verapamil were performed using permethrin at the six concentrations indicated above, plus two additional 
concentrations $(0.0024$ and $0.0048 \mathrm{mg} / \mathrm{l})$. The sub-lethal dose of verapamil (i.e. the dose at which no dead larvae were observed) was determined using ten different concentrations $(20,40,80,100,160,240,320,400,480$, $560 \mu \mathrm{M})$ following the protocol above. The larval mortality data were subjected to Probit regression analysis [24] as implemented in the XLSTAT-Dose software (available at: http://www.xlstat.com) to estimate the LD50 values and their 95\% confidence intervals (CIs). To estimate the effect on larval mortality of the $\mathrm{ABC}$ inhibitor at sub-lethal dose, the synergistic factor (SF) was calculated.

\section{Identification of $A B C$ transporter genes}

A total of 200 untreated larvae of An. stephensi at the third instar were pooled in $15 \mathrm{ml}$ of RNAlater stabilization solution (Qiagen, Hilden, Germany) and provided to an external company (GATC Biotech AG, Costance, Germany) for one run of 2x250 paired-ends reads sequencing on the Illumina MiSeq platform. The resulting reads were assembled using Trinity with default settings [25]. The assembled contigs were compared with Blastx (evalue 0.00001) to the annotated transcriptome of An. gambiae available in the VectorBase database, and the sequences of $\mathrm{ABC}$ transporters were extracted automatically and manually controlled. Based on published results about the involvement of $\mathrm{ABCs}$ on multidrug resistance in several arthropods (mainly mosquitoes) [8], we selected five genes from the transcriptome of An. stephensi. Oligonucleotide primers were then designed from the sequence of each gene (Table 1). The sequences of $\mathrm{ABC}$ transporters identified in An. stephensi were translated to aminoacids and compared against the UniProt database [26] using Blastp. Homologous proteins were aligned using ClustalX [27] and distances among them were estimated by Dayhoff PAM matrix as implemented in the PROTDIST software of the PHYLIP package [28].

\section{Gene expression profile after insecticide treatment}

The activity of $\mathrm{ABC}$-transporters is generally modulated at gene transcriptional level: the presence of toxic compounds leads to higher transcription. In order to assess this topic, larvae of An. stephensi at the third instar were exposed to permethrin and the expression of $\mathrm{ABC}$ transporter genes was monitored in the surviving larvae by quantitative RT-PCR twice after insecticide treatment: $24 \mathrm{~h}$ (e.g. the time at which the LD50 has been estimated) and $48 \mathrm{~h}$ following the study of Figueira-Mansur [29] that found increased expression of $A B C$ transporters in the mosquito Ae aegypti. The larvae were treated with the LD50 $(0.137 \mathrm{mg} / \mathrm{l})$ of insecticide estimated by bioassays as described above and two pools, of ten larvae each, were collected after 24 and $48 \mathrm{~h}$ of insecticide-treatment. All pools of larvae were stored in RNAlater for molecular analysis and, controls (water + acetone) were collected following the same time frame.

RNA was extracted from each pool of larvae using the RNeasy Mini Kit (Qiagen, Hilden, Germany) including an on-column DNase I treatment (Qiagen, Hilden, Germany), according to the manufacturer's instructions. Total RNA was eluted into nuclease-free water and the concentration of RNA was determined at $260 \mathrm{~nm}$ [30] using a NanoDrop ND-1000 (Thermo Scientific, Delaware, USA). cDNAs were synthesized from 250 ng of total RNA using a QuantiTect Reverse Transcription Kit (Qiagen, Hilden, Germany) with random hexamers. The cDNA was used as template in RT-PCR reactions using the primers designed from the sequences of identified $A B C$ genes (Table 1). The amplification fragments, obtained using standard PCR conditions and the thermal profile indicated below, were sequenced in order to confirm the specificity of the amplification.

Quantitative RT-PCRs on the target ABCs were performed using a BioRad iQ5 Real-Time PCR Detection System (Bio-Rad, California, USA), under the following conditions: $50 \mathrm{ng}$ cDNA; $300 \mathrm{nM}$ of forward and reverse primers; $98^{\circ} \mathrm{C}$ for $30 \mathrm{sec}, 40$ cycles of $98^{\circ} \mathrm{C}$ for $15 \mathrm{sec}$, $59^{\circ} \mathrm{C}$ for $30 \mathrm{sec}$; fluorescence acquisition at the end of each cycle; melting curve analysis after the last cycle. The cycle threshold $(\mathrm{Ct})$ values were determined for each gene, in order to calculate gene expression levels of target genes relative to rps 7 , the internal reference gene for An. stephensi [31]. The expression of the ABC transporters genes in the control group was considered as the basal level (equal to 1). The estimates of the expression level of each gene in the treated larvae are reported as

Table 1 Primer sequences of ABC transporter genes identified in Anopheles stephensi

\begin{tabular}{lllcc}
\hline Gene & Forward primer & Reverse primer & PCR product size (base pairs) & Source \\
\hline AnstABCB2 & TATCAAGTCACGGATGTAGAGT & TATCCACCTTGCCACTGTC & 185 & This work \\
AnstABCB3 & CAACCGTTCCGTAATACTACC & ACTGGTAGCCAATGTGAAG & 133 & This work \\
AnstABCB4 & GGACAAAACATTCGGGAGG & CGTAGTGAATGTTGGGCG & 109 & This work \\
AnstABCBmemb6 & CTGGAGACGCTGAGAGATA & TACTCCTCGGTGAACTGG & 125 & This work \\
AnstABCG4 & ATGAGCCCATTCGTCCTG & AGCGTGGAGAAGAAGCAG & 158 & This work \\
Rps7 & AGCAGCAGCAGCACTTGATTTG & TAAACGGCTTCTGCGTCACCC & 90 & Capone et al. 2013 [31] \\
\hline
\end{tabular}


the means \pm standard deviation (SD) in Additional file 1: Table S1.

\section{Ethical statement}

Maintenance of the mosquito colony of An. stephensi was carried out according the Italian Directive 116 of $10 / 27 / 92$ on the "use and protection of laboratory animals" and in adherence with the European regulation (86/609) of $11 / 24 / 86$ (licence no. 125/94A, issued by the Italian Ministry of Health).

\section{Results}

Bioassays

No mortality was observed when larvae were exposed at concentrations of verapamil up to $100 \mu \mathrm{M}$; this concentration was thus used as the sub-lethal dose in the bioassays with insecticide $+\mathrm{ABC}$-transporter inhibitor. The results of toxicity assays using permethrin and permethrin in combination with verapamil are reported in Table 2. The mortality data observed in bioassays well fitted the Probit dose-response model (Chi-Square probability $<0.0001)$. The LD50 dose in permethrin assay was $0.137 \mathrm{mg} / \mathrm{l}$ while in the assay in combination with verapamil LD50 was $0.025 \mathrm{mg} / \mathrm{l}$ (Table 2). No overlapping values were observed between LD50 95\% CI of insecticide alone and insecticide plus verapamil; the addition of verapamil increased the toxicity of permethrin about 5 -fold $(\mathrm{SF}=5.48)$.

\section{Isolation of $A B C$ transporter genes and expression profile after insecticide treatment}

The Illumina MiSeq platform was used to sequence the cDNA library obtained from a pool of 200 larvae of $A n$. stephensi, and 16,686,276 paired-ends reads were obtained. MiSeq raw data were assembled with Trinity, obtaining 40,498 contigs. The contigs containing ABC transporter genes were extracted on the basis of the annotated transcriptome of An. gambiae available in database. Five sequences, respectively of 3612, 2154, 2481, 2553 and 2182 base pairs, were found to share $85-94 \%$ identity with putative $\mathrm{ABC}$ multidrug transporters of $A n$.

Table 2 Toxicity of verapamil and permethrin against Anopheles stephensi larvae

\begin{tabular}{lclll}
\hline Insecticide & $\mathbf{N}$ & Slope \pm SE & LD50 $(\mathbf{9 5 \%} \mathbf{C l})$ & SF \\
\hline Verapamil & 600 & $3.846(0.374)^{*}$ & $528 \mu \mathrm{M}(486-587)$ & \\
Permethrin & 600 & $1.819(0.125)^{*}$ & $\begin{array}{l}0.137 \mathrm{mg} / \mathrm{l} \\
(0.117-0.160)\end{array}$ & \\
& & & $0.025 \mathrm{mg} / \mathrm{l}$ & 5.48 \\
$\begin{array}{l}\text { Permethrin + verapamil } \\
(100 \mu \mathrm{M})\end{array}$ & 600 & $2.123(0.174)^{*}$ & $(0.021-0.029)$ &
\end{tabular}

LD50 and slopes of regression lines estimated from mortality data by Probit analysis are shown. N, number of larvae used in bioassays; SE, standard error; 95\% $\mathrm{Cl}, 95 \%$ confidence interval. SF, synergistic factor.

${ }^{*}$ Chi-Square probability $<0.0001$. gambiae: ABCB2 (AGAP005639) (85\% identity), ABCB3 (AGAP006273) (94\% identity), ABCB4 (AGAP006364) (88\% identity), ABCmember6 (AGAP002278) (94\% identity) and ABCG4 (AGAP001333) (85\% identity). We denoted them as AnstABCB2, AnstABCB3, AnstABCB4, AnstABCmember6, AnstABCG4 and we deposited them in EMBL Nucleotide Sequence Database [EMBL: LK392613 to LK392617]. The alignment of the deduced amino acidic sequences of $\mathrm{ABC}$ transporters identified in An. stephensi with sequences of homologous $\mathrm{ABC}$ transporters of $A n$. gambiae is shown in Additional file 2: Figure S1. Dayhoff PAM distance estimates between the $\mathrm{ABC}$ transporters identified in An. stephensi and the homologous ABC transporters of mosquitoes An. gambiae, Anopheles darlingi, Ae. aegypti and Culex quinquefasciatus that showed the highest percentage of identity following Blast search are shown in Additional file 3: Table S2.

Conventional PCR amplicons obtained from each gene primer set were sequenced, confirming in all cases the sequences generated with the MiSEQ experiment. The RT-PCRs were performed to investigate whether permethrin treatment at the LD50 dose $(0.137 \mathrm{mg} / \mathrm{l}$, Table 2) increased or decreased the $\mathrm{ABC}$ gene expression in the An. stephensi larvae after 24 and $48 \mathrm{~h}$ of insecticidetreatment. As reported in Figure 1 and Additional file 1: Table S1, after $24 \mathrm{~h}$ of permethrin treatment, the relative expression of all selected genes was down-regulated, with the exception of the AnstABCG4 gene, that showed about three-fold increase of expression compared to the control. Similarly, after $48 \mathrm{~h}$ of permethrin treatment, the relative expression of all $\mathrm{ABCB}$ genes was downregulated, while the AnstABCG4 gene showed a ten-fold increase of expression compared to the control.

\section{Discussion}

Bioassays and molecular data suggest the involvement of $\mathrm{ABC}$ transporters in the defense of An. stephensi larvae against the permethrin insecticide. Indeed, inhibition of $\mathrm{ABC}$-transporters led to a higher susceptibility of larvae to insecticide, indicating that $\mathrm{ABC}$ transporters are associated with insecticide detoxification. In addition, in mosquito larvae exposed to the LD50 dose of permethrin, we observed an increased expression of AnstABCG4, one of the five tested genes coding for $\mathrm{ABC}$ transporters.

Arthropod ABCG genes are orthologous of the human gene $A B C G 2$, which has been associated with resistance to cancer drugs [32,33], while data in insects show that $A B C G$ transporter genes were significantly over-transcribed in response to exposure to insecticides. Microarray gene expression studies revealed that ABCG transporter genes were up-regulated in DDT resistant strains of Drosophila melanogaster [34] and in a Plutella xylostella (Lepidoptera) strain resistant to chlorpyrifos [35]. The ABCG4 transporter gene was over-transcribed in Bemisia tabaci whiteflies resistant to 


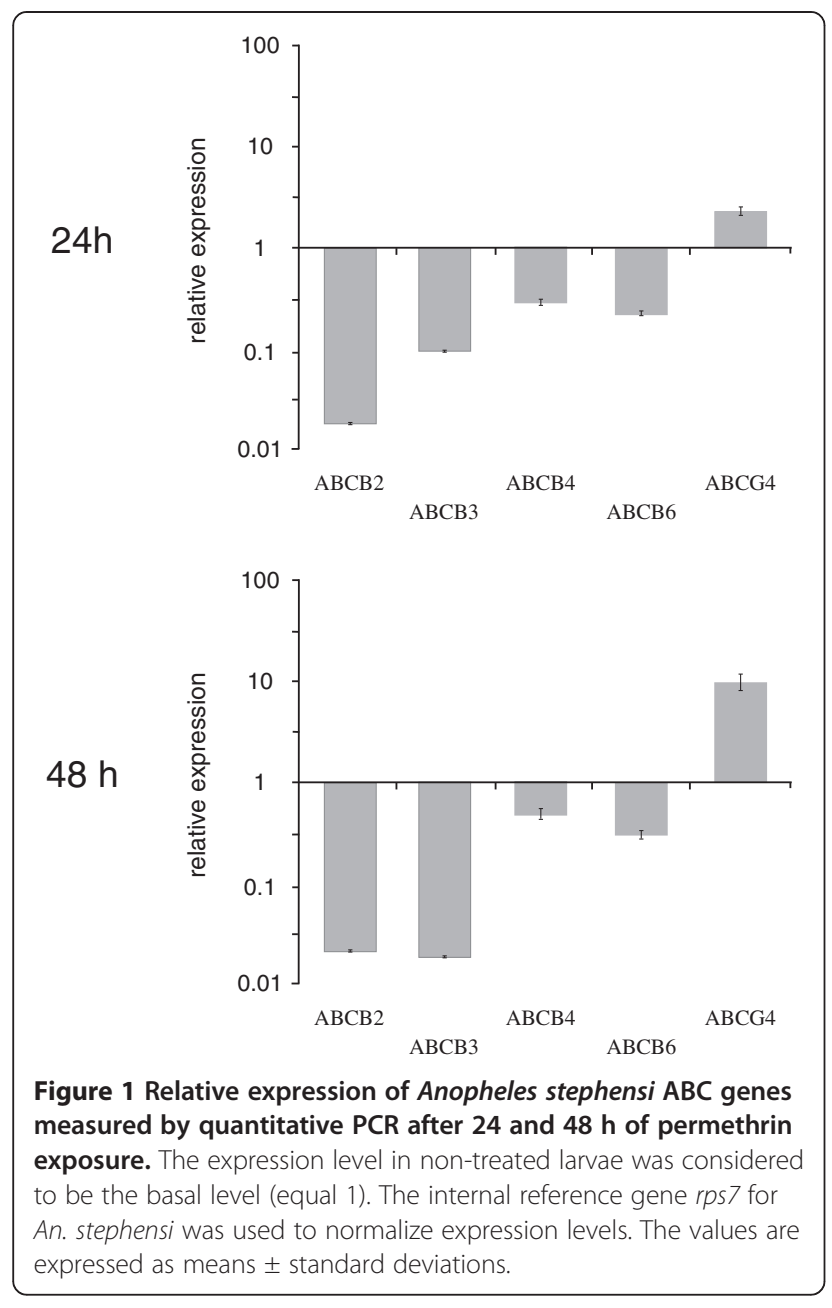

the neonicotinoid thiamethoxam [36] as well as in Anopheles arabiensis resistant- and sensible-strains to DDT [33]. The ABCG3 gene was found differentially expressed in $A e$. aegypti pyrethroid resistant populations versus susceptible strains [21].

The other four genes coding for $\mathrm{ABC}$ transporters that we detected and tested in An. stephensi (AnstABCB2, AnstABCB3, AnstABCB4 and AnstABCmember6) belong to the $A B C B$ subfamily. Several members of this subfamily have been associated with transport and/or resistance to different insecticide classes in several insect species $[7,8]$. In mosquitoes, the ABCB2 gene was showed by quantitative PCR to be eightfold up-regulated in larvae of a susceptible strain of Ae. aegypti analysed at $48 \mathrm{~h}$ post temephos-treatment [29]. The ABCB4 gene was showed to be over-transcribed by transcriptome and quantitative PCR analyses, in DDT and pyrethroid (permethrin and deltamethrin) resistant Ae. aegypti populations compared to a laboratory susceptible population [21]. Microarray analysis showed that the ABCB4 was upregulated in different populations of DDT-resistant $A n$. gambiae mosquitoes [37]. Our results showed no over- transcription of the ABCB genes in An. stephensi susceptible larvae exposed to permethrin, while insecticide treatment induced an increased expression of the AnstABCG4 (Figure 1, Additional file 1: Table S1).

On the whole, the results herein presented support the view of the involvement of $A B C$ transporters in insecticide transport, although differences with previous studies have been observed. Are these differences due to the insecticides used or to the status of the analysed samples (i.e. susceptible vs. resistant)? Despite the growing number of studies on $A B C$ transporters in insects, the heterogeneity of the data available at present does not allow to infer general trends that may underlie particular interactions between $\mathrm{ABC}$ transporters and insecticides. Further studies are needed to highlight these and other issues. For example, our results showed that the expression of $\mathrm{ABCB}$ genes in An. stephensi did not only increase in larvae treated with permethrin compared to those non-treated, but indeed it decreased (Figure 1, Additional file 1: Table S1). In the latter case, the study of gene expression at more time points could contribute to the understanding of whether there are temporal delays, or whether compound-specific or species-specific differences exist in their activation [38-40]. Furthermore, most studies have been conducted on larval stages $[7,8]$. The synergist and transcript profiles may differ between larval and adult stages, an interesting topic for future studies.

Diffusion of vectors of human diseases driven by human activities and global climate change as well as insurgence of insecticide resistance can seriously impact our ability to control vector-borne diseases [41-44]. Furthermore, environmental pollution and resistance phenomena clearly show the limits of the chemical approach for pest control and the need to delineate new strategies that optimize the use of available molecules, with the aim of reducing their impact on the environment [31,45-48].

In the last decades advances in molecular techniques have greatly improved our tools to investigate the dynamics of vector populations and of pesticide resistance insurgence [43,49-53]. More recently, next-generation sequencing technologies have offered unprecedented opportunities to investigate the molecular basis of the interaction between cellular defenses and insecticides [54]. In this context, the increasing interest about $A B C$ transporters in transport and/or resistance against insecticides led to an increase of the information on these genes in various insect species and their association with insecticide detoxification $[7,8]$.

\section{Conclusions}

In this study we have demonstrated for the first time in the larvae of An. stephensi that verapamil increases the sensitivity to permethrin in laboratory assays; in addition, 
we isolated five genes encoding for $\mathrm{ABC}$ transporters, and investigated their expression profile after exposure to permethrin. To analyse the potential role of $\mathrm{ABC}$ transporters in permethrin transport in An. stephensi, we performed bioassays using a sub-lethal dose of the $\mathrm{ABC}$ transporter inhibitor verapamil in association with permethrin. The results obtained using this approach highlight that the combination of insecticides with an $\mathrm{ABC}$-transporter inhibitor can increase the efficacy of the insecticide molecule $[18,29,55]$. In prospect, combined treatments of insecticide plus $\mathrm{ABC}$-transporter inhibitors could be proposed, with the objective of reducing the current dosages of insecticides or to prevent the development of resistance, and reduce environmental pollution $[29,56]$. The implementation of such a strategy would require the availability of gene- and species-specific inhibitors in order to avoid the serious consequences that would derive from a generic inhibition of $\mathrm{ABC}$-transporters in non-target organisms. The study of ABC-transporters at the gene level is therefore crucial for the understanding of both their potential role as defense mechanisms and for their inhibition for vector control purposes.

\section{Additional files}

Additional file 1: Table S1. Relative expression of Anopheles stephensi $A B C$ genes measured by quantitative PCR after permethrin exposure. The expression level in non-treated larvae was considered to be the basal level (equal 1). The internal reference gene rps 7 for An. stephensi was used to normalize expression levels. The values are expressed as means \pm standard deviations.

Additional file 2: Figure S1. Alignment by ClustalW of deduced amino acidic sequences of ABC transporters of Anopheles stephensi and Anopheles gambiae. Asterisks: conserved amino acid residues; colons: conserved substitutions; dots: semiconserved substitutions.

Additional file 3: Table S2. Dayhoff PAM matrix. Estimates of distance among the $A B C$ transporters identified in Anopheles stephensi and the homologous $A B C$ transporters of other mosquitoes species are shown: An. gambiae (AGAP005639; AGAP006273; AGAP006364; AGAP002278; AP001333), An. darlingi (ETN61204; ETN66919; ETN62617; ETN64062; ETN58714), Aedes aegypti (AAEL010379; AAEL002468; AAEL006717; AAEL008134; AAEL003703), and Culex quinquefasciatus (EDS44274; EDS35382; EDS29700; EDS27088; EDS37204).

\section{Competing interests}

The authors declare that they have no competing interests.

\section{Authors' contributions}

$S E, D P, V M$ conceived the study, performed the experiments and contributed to data analysis, interpretation and manuscript writing. FC and DS performed the bioinformatic analyses; PR, GF and CF contributed to sample collection. DO, CG, CB and SU contributed to data interpretation and manuscript writing. All authors read and approved the final version of the manuscript.

\section{Acknowledgements}

The authors are grateful to Dr. Valeria Mereghetti, Dr. Daniele Facchi and Dr. Massimo Pajoro for providing assistance to accomplish this research. This work was supported by MIUR Prin 2010-2011 (to C. Genchi).

\section{Author details}

'Department of Veterinary Science and Public Health, University of Milan, Milan, Italy. ${ }^{2}$ Department of Environmental Biology, University "La Sapienza" of Rome, Rome, Italy. ${ }^{3}$ Department of Biology and Biotechnology, University of Pavia, Pavia, Italy. ${ }^{4}$ School of Bioscience and Veterinary Medicine,

University of Camerino, Camerino, Italy. ${ }^{5}$ Department of Veterinary Medicine, University of Bari, Bari, Italy.

Received: 5 June 2014 Accepted: 15 July 2014

Published: 29 July 2014

\section{References}

1. Hay SI, Guerra CA, Tatem AJ, Noor AM, Snow RW: The global distribution and population at risk of malaria: past, present, and future. Lancet Infect Dis 2004, 4:327-336. 1.

2. World Health Organization: World malaria report 2012. www.who.int/ malaria/publications/world_malaria_report_2012/report/en/.

3. Alonso $\mathrm{PL}$, Tanner M: Public health challenges and prospects for malaria control and elimination. Nat Med 2013, 19(2):150-155.

4. Karunamoorthi $\mathrm{K}$ : Vector control: a cornerstone in the malaria elimination campaign. Clin Microbiol Infect 2011, 17:1608-1616.

5. Tikar SN, Mendki MJ, Sharma AK, Sukumaran D, Veer V, Prakash S, Parashar BD: Resistance status of the malaria vector mosquitoes, Anopheles stephensi and Anopheles subpictus towards adulticides and larvicides in arid and semi-arid areas of India. J Insect Sci 2011, 11:85.

6. Perry T, Batterham P, Daborn PJ: The biology of insecticidal activity and resistance. Insect Biochem Mol Biol 2011, 41:411-422.

7. Buss DS, Callaghan A: Interaction of pesticides with p-glycoprotein and other $A B C$ proteins: a survey of the possible importance to insecticide, herbicide and fungicide resistance. Pestic Biochem Physiol 2008, 90:141-153.

8. Dermauw W, Van Leeuwen $\mathrm{T}$ : The $A B C$ gene family in arthropods: comparative genomics and role in insecticide transport and resistance. Insect Biochem Mol Bio 2014, 45:89-110.

9. Sinka ME, Bangs MJ, Manguin S, Chareonviriyaphap C, Patil AP, Temperley WH, Gething PW, Elyazar IRF, Kabaria CW, Harbach RE, Hay SI: The dominant anopheles vectors of human malaria in Asia-Pacific: occurrence data, distribution maps and bionomic précis. Parasit Vectors 2011, 4:89.

10. Soderlund DM: Pyrethroids, knockdown resistance and sodium channels. Pest Manag Sci 2008, 64:610-616.

11. Schleier JJ III, Peterson RKD: Pyrethrins and Pyrethroid Insecticides. In Green Trends in Insect Control. Edited by Lopez O, Fernandez-Bolanos JG. London, UK: Royal Society of Chemistry; 2011:94-131.

12. Mayer F, Mayer N, Chinn L, Pinsonneault RL, Kroetz D, Bainton RJ: Evolutionary conservation of vertebrate blood-brain barrier chemoprotective mechanisms in Drosophila. J Neurosci 2009, 29:3538-3550.

13. Andersson O, Badisco L, Hakans Son Hansen A, Hansen SH, Hellman K, Nielsen PA, Olsen LR, Verdonck R, Abbott NJ, Vanden Broeck J, Andersson G: Characterization of a novel brain barrier ex vivo insect-based P-glycoprotein screening model. Pharma Res Per 2014, 2(4):e00050.

14. Srinivas R, Shamsundar GS, Jayalakshmi SK, Sreermalu K: Effect of insecticides and inhibitors on P-glycoprotein ATPase (M-type) activity of resistant pest Helicoverpa armigera. Curr Sci 2005, 88:1449-1452.

15. Aurade R, Jayalaksh mi SK, Sreeramulu K: Stimulatory effect of insecticides on partially purified P-glycoprotein ATPase from the resistant pest Helicoverpa armigera. Biochem Cell Biol 2006, 84:1045-1050.

16. Aurade RM, Jayalak shmi SK, Sreeramulu K: P-glycoprotein ATPase from the resistan pest, Helicoverpa armigera: purification, characterization and effect of various insecticides on its transport function. Biochim Biophys Acta 2010, 1798:1135-1143.

17. Hawthorne DJ, Dively GP: Killing them with kindness? In-hive medications may inhibit xenobiotic efflux transporters and endanger honey bees. PLoS One 2011, 6:e26796.

18. Buss DS, McCaffery AR, Callaghan A: Evidence for p-glycoprotein modification of insecticide toxicity in mosquitoes of the Culex pipiens complex. Med Vet Entomol 2002, 16(2):218-222.

19. Zhu F, Gujar H, Gordon JR, Haynes KF, Potter MF, Palli SR: Bed bugs evolved unique adaptive strategy to resist pyrethroid insecticides. $\mathrm{SCi}$ Rep 2013, 3:1456.

20. Bonizzoni M, Afrane Y, Dunn WA, Atieli FK, Zhou G, Zhong D, Li J, Githeko A, Yan G: Comparative transcriptome analyses of deltamethrin-resistant and -susceptible Anopheles gambiae mosquitoes from Kenya by RNA-Seq. PLoS One 2012, 7:e44607.

21. Bariami V, Jones CM, Poupardin R, Vontas J, Ranson H: Gene amplification, $A B C$ transporters and cytochrome P450s: unraveling the molecular basis 
of pyrethroid resistance in the dengue vector, Aedes aegypti. PLOS Negl Trop Dis 2012, 6:e1692.

22. Thomas H, Coley HM: Overcoming multidrug resistance in cancer: an update on the clinical strategy of inhibiting P-glycoprotein. Cancer Control 2003, 10(02):159-165.

23. World Health Organization: Guidelines for Laboratory and Field Testing of Mosquito Larvicides. Communicable Disease Control, Prevention and Eradication, WHO Pesticide Evaluation Scheme. Geneva: WHO; 2005. WHO/ CDS/WHOPES/GCDPP/2005.13.

24. Finney DJ: Probit Analysis. Cambridge: Cambridge University Press; 1971.

25. Grabherr MG, Haas BJ, Yassour M, Levin JZ, Thompson DA, Amit I, Adiconis X, Fan L, Raychowdhury R, Zeng Q, Chen Z, Mauceli E, Hacohen N, Gnirke A Rhind N, di Palma F, Birren BW, Nusbaum C, Lindblad-Toh K, Friedman N, Regev A: Full-length transcriptome assembly from RNA-Seq data without a reference genome. Nat Biotechnol 2011, 29:644-652.

26. Uniprot_Consortium: activities at the Universal Protein Resource (UniProt). Nucleic Acids Res 2014, 42:D191-D198.

27. Thompson JD, Gibson TJ, Plewniak F, Jeanmougin F, Higgins DG: The CLUSTAL_X windows interface: flexible strategies for multiple sequence alignment aided by quality analysis tools. Nucleic Acids Res 1997, 25(24):4876-4882

28. Felsenstein J: PHYLIP - phylogeny inference package (version 3.2). Cladistics 1989, 5:164-166.

29. Figueira-Mansur J, Ferreira-Pereira A, Mansur JF, Franco TA, Alvarenga ES, Sorgine MH, Neves BC, Melo AC, Leal WS, Masuda H, Moreira MF: Silencing of P-glycoprotein increases mortality in temephos-treated Aedes aegypti larvae. Insect Mol Biol 2013, 22(6):648-658.

30. Lee EJ, Schmittgen TD: Comparison of RNA assay methods used to normalize cDNA for quantitative real-time PCR. Anal Biochem 2006, 357(2):299-301.

31. Capone A, Ricci I, Damiani C, Mosca M, Rossi P, Scuppa P, Crotti E, Epis S, Angeletti M, Valzano M, Sacchi L, Bandi C, Daffonchio D, Mandrioli M, Favia G: Interactions between Asaia, Plasmodium and Anopheles: new insights into mosquito symbiosis and implications in malaria symbiotic control. Parasit Vectors 2013, 6:182

32. Tarr PT, Tarling EJ, Bojanic DD, Edwards PA, Baldan A: Emerging new paradigms for ABCG transporters. Biochim Biophys Acta 2009, 1791(7):584-593.

33. Jones CM, Toé HK, Sanou A, Namountougou M, Hughes A, Diabaté A Dabiré $\mathrm{R}$, Simard F, Ranson H: Additional selection for insecticide resistance in urban malaria vectors: DDT resistance in Anopheles arabiensis from Bobo-Dioulasso, Burkina Faso. PLoS One 2012, 7(9):e45995.

34. Pedra JHF, Mclntyre LM, Scharf ME, Pittendrigh BR: Genome-wide transcription profile of field- and laboratory-selected dichlorodiphenyltrichloroethane (DDT) resistant Drosophila. Proc Natl Acad Sci U S A 2004 101:7034-7039.

35. You M, Yue Z, He W, Yang X, Yang G, Xie M, Zhan D, Baxter SW, Vasseur L, Gurr GM, Douglas CJ, Bai J, Wang P, Cui K, Huang S, Li X, Zhou Q, Wu Z, Chen Q, Liu C, Wang B, Li X, Xu X, Lu C, Hu M, Davey JW, Smith SM, Chen M, Xia $X$, Tang $W$, et al: $A$ heterozygous moth genome provides insights into herbivory and detoxification. Nat Genet 2013, 45(2):220-225.

36. Yang $N$, Xie W, Yang X, Wang S, Wu Q, Li R, Pan H, Liu B, Shi X, Fang Y, Xu B, Zhou $X$, Zhang $Y$ : Transcriptomic and proteomic responses of sweetpotato whitefly, Bemisia tabaci, to thiamethoxam. PLoS One 2013, 8(5):e61820.

37. Fossog Tene B, Poupardin R, Costantini C, Awono-Ambene P, Wondji CS, Ranson $\mathrm{H}$, Antonio-Nkondjio C: Resistance to DDT in an urban setting: common mechanisms implicated in both $\mathrm{M}$ and $\mathrm{S}$ forms of Anopheles gambiae in the city of Yaoundé Cameroon. PLoS One 2013, 8(4):e61408.

38. Hayashi K, Schoonbeek H, Sugiura H, De Waard MA: Multidrug resistance in Botrytis cinerea associated with decreased accumulation of the azole fungicide oxpoconazole and increased transcription of the $A B C$ transporter gene BcatrD. Pestic Biochem Physiol 2001, 70:168-179.

39. Urbanelli S, Della Rosa V, Punelli F, Porretta D, Reverberi M, Fabbri AA, Fanelli C: DNA-fingerprinting (AFLP and RFLP) for genotypic identification in species of the Pleurotus eryngii complex. Appl Microbiol Biotechnol 2007, 74(3):592-600.

40. Punelli F, Reverberi M, Porretta D, Nogarotto S, Fabbri A, Fanelli C, Urbanelli S: Molecular characterization and enzymatic activity of laccases in two Pleurotus spp. with different pathogenic behavior. Mycol Res 2009, 113:381-387.

41. Dantas-Torres F, Figueredo LA, Otranto D: Seasonal variation in the effect of climate on the biology of Rhipicephalus sanguineus in southern Europe. Parasitology 2011, 138:527-536.
42. Porretta D, Mastrantonio V, Bellini R, Somboon P, Urbanelli S: Glacial history of a modern invader: phylogeography and species distribution modelling of the asian tiger mosquito Aedes albopictus. Plos One 2012, 7(9):e44515.

43. Porretta D, Mastrantonio V, Amendolia S, Gaiarsa S, Epis S, Genchi C, Bandi C, Otranto D, Urbanelli S: Effects of global changes on the climatic niche of the tick Ixodes ricinus inferred by species distribution modelling. Parasit Vectors 2013, 6:271.

44. Steele J, Orsel K, Cuyler C, Hoberg EP, Schmidt NM, Kutz SJ: Divergent parasite faunas in adjacent populations of west Greenland caribou: natural and anthropogenic influences on diversity. Int J Parasitol Parasites Wildl 2013, 2:197-202.

45. Porretta D, Canestrelli D, Bellini R, Celli G, Urbanelli S: Improving insect pest management through population genetic data: a case study of the mosquito Ochlerotatus caspius (Pallas). J Appl Ecol 2007, 44:682-691.

46. Otranto D, Wall R: New strategies for the control of arthropod vectors of disease in dogs and cats. Med Vet Entomol 2008, 22:291-302.

47. Calvitti M, Moretti R, Porretta D, Bellini R, Urbanelli S: Effects on male fitness of removing wolbachia infections from the mosquito aedes albopictus. Med Vet Entomol 2009, 23(2):132-140.

48. Bouyer F, Hamadou S, Adakal H, Lancelot R, Stachurski F, Belem AM, Bouyer J: Restricted application of insecticides: a promising tsetse control technique, but what do the farmers think of it? PLOS Negl Trop Dis 2011, 5(8):e1276.

49. Marcombe S, Poupardin R, Darriet F, Reynaud S, Bonnet J, Strode C, Brengues C, Yébakima A, Ranson H, Corbel V, David JP: Exploring the molecular basis of insecticide resistance in the dengue vector Aedes aegypti: a case study in Martinique Island (French West Indies). BMC Genomics 2009, 10:494.

50. Bellini R, Albieri A, Balestrino F, Carrieri M, Porretta D, Urbanelli S, Calvitti M, Moretti R, Maini S: Dispersal and survival of Aedes albopictus (Diptera: Culicidae) males in Italian urban areas and significance for sterile insect technique application. J Med Entomol 2010, 47(6):1082-1091.

51. Porretta D, Canestrelli D, Urbanelli S, Bellini R, Schaffner F, Petric D, Nascetti G: Southern crossroads of the Western Palaearctic during the late pleistocene and their imprints on current patterns of genetic diversity: insights from the mosquito Aedes caspius. J Biogeogr 2011, 38:20-30.

52. Kennedy C, Tierney K: Xenobiotic Protection/Resistance Mechanisms in Organisms. New York: E.A Laws, Environ Toxicol: Springer; 2013.

53. Porretta D, Mastrantonio V, Mona S, Epis S, Montagna M, Sassera D, Bandi C, Urbanelli S: The integration of multiple independent data reveals an unusual response to pleistocene climatic changes in the hard tick Ixodes ricinus. Mol ECO 2013, 22(6):1666-1682.

54. Jones CM, Haji KA, Khatib BO, Bagi J, Mcha J, Devine GJ, Daley M, Kabula B, Ali AS, Majambere $S$, Ranson $\mathrm{H}$ : The dynamics of pyrethroid resistance in Anopheles arabiensis from Zanzibar and an assessment of the underlying genetic basis. Parasit Vectors 2013, 6:343.

55. Porretta D, Gargani M, Bellini R, Medici A, Punelli F, Urbanelli S: Defence mechanism against insecticides temephos and diflubenzuron in the mosquito Aedes caspius: the P-glycoprotein efflux pumps. Med Vet Entomol 2008, 22:48-54.

56. Pohl PC, Klafke GM, Carvalho DD, Martins JR, Daffre S, da Silva Vaz I Jr, Masuda $A: A B C$ transporter efflux pumps: a defence mechanism against ivermectin in Rhipicephalus (Boophilus) microplus. Int J Parasitol 2011, 41:1323-1333.

doi:10.1186/1756-3305-7-349

Cite this article as: Epis et al:: $A B C$ transporters are involved in defense against permethrin insecticide in the malaria vector Anopheles stephensi. Parasites \& Vectors 2014 7:349. 